
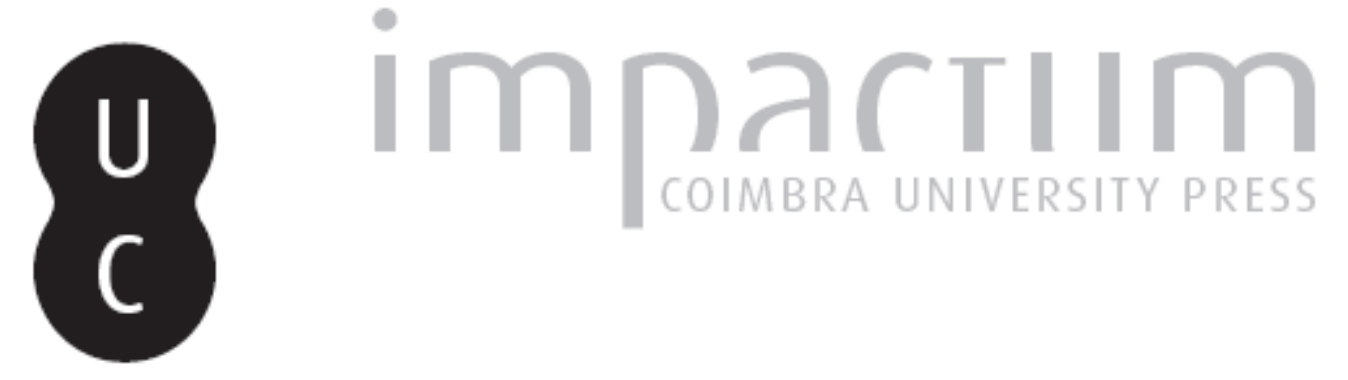

\title{
Da "Débil Presença" ao Fait Accompli: a Organização das Nações Unidas e a Descolonização Portuguesa
}

\author{
Autor(es): $\quad$ Santos, Aurora Almada e
}

Publicado por: Imprensa da Universidade de Coimbra

URL persistente:

URI:http://hdl.handle.net/10316.2/44857

DOI:

DOI:https://doi.org/10.14195/1647-8622_18_6

Accessed : $\quad$ 26-Apr-2023 14:19:49

A navegação consulta e descarregamento dos títulos inseridos nas Bibliotecas Digitais UC Digitalis, UC Pombalina e UC Impactum, pressupõem a aceitação plena e sem reservas dos Termos e Condições de Uso destas Bibliotecas Digitais, disponíveis em https://digitalis.uc.pt/pt-pt/termos.

Conforme exposto nos referidos Termos e Condições de Uso, o descarregamento de títulos de acesso restrito requer uma licença válida de autorização devendo o utilizador aceder ao(s) documento(s) a partir de um endereço de IP da instituição detentora da supramencionada licença.

Ao utilizador é apenas permitido o descarregamento para uso pessoal, pelo que o emprego do(s) título(s) descarregado(s) para outro fim, designadamente comercial, carece de autorização do respetivo autor ou editor da obra.

Na medida em que todas as obras da UC Digitalis se encontram protegidas pelo Código do Direito de Autor e Direitos Conexos e demais legislação aplicável, toda a cópia, parcial ou total, deste documento, nos casos em que é legalmente admitida, deverá conter ou fazer-se acompanhar por este aviso.

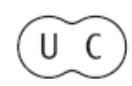




\section{ESTUDOSDOSÉCULO}

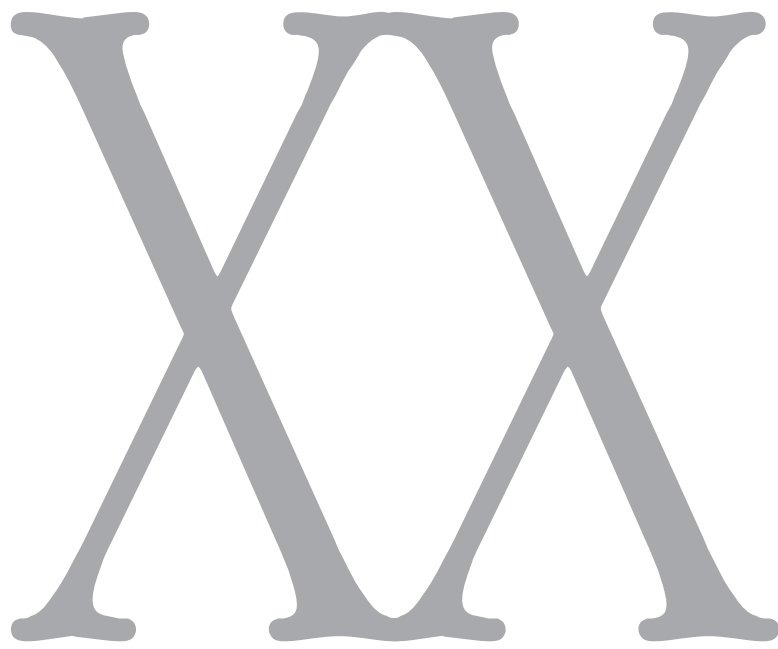

número $18 \bullet 2018$

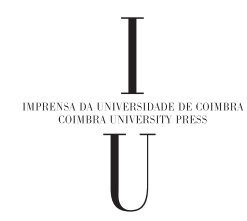




\title{
Da "Débil Presença" ao Fait Accompli A Organização das Naçóes Unidas e a Descolonização Portuguesa
}

\section{From "Weak Presence” to Fait Accompli The United Nations and the Portuguese Decolonization}

\author{
Aurora Almada e Santos
}

Aurora Almada e Santos, Investigadora do Instituto de História Contemporânea da Universidade Nova de Lisboa. Email: auroraalmada@yahoo.com.br. 
DA “DÉBIL PRESENÇA” AO FAIT ACCOMPLI:

A ORGANIZAÇÃO DAS NA-

ÇÓES UNIDAS E A

DESCOLONIZAÇÃO

PORTUGUESA

Ao envolver-se na questão colonial portuguesa, a Organização das Naçóes Unidas intensificou as suas iniciativas com o início da guerra em Angola e, posteriormente, nas vésperas da descolonização. Sem negar a importância de outros fatores, pretendemos estudar o impacto das açóes desenvolvidas pelas Naçóes Unidas na independência das colónias portuguesas. O núcleo central do artigo será constituído pelo intervalo de tempo compreendido entre a mudança de regime em Portugal com o 25 de Abril e a admissão de Angola, em dezembro de 1976, como membro da Organizaçáo. A análise reportar-se-á num primeiro momento ao interesse das Naçôes Unidas em participar no processo de descolonização e à recusa do seu contributo por Portugal e pelos movimentos de libertação. $\mathrm{O}$ segundo momento remeter-nos-á para o período em que o governo português passou a solicitar a intervenção da Organização e em que foi confrontado com os receios do secretário-geral, Kurt Waldheim, quanto a um eventual comprometimento com a situaçáo em Timor e Angola. Subjacente ao artigo estará a tentativa de desmistificar o entendimento que tem sido propagada segundo o qual as Naçōes Unidas não participaram no processo de descolonizaçáo português.

Palavras-chave: Organização das Naçôes Unidas; Portugal; Colónias Portuguesas; Autodeterminação; Independência
FROM "WEAK PRESENCE" TO FAIT ACCOMPLI: THE UNITED NATIONS AND THE PORTUGUESE DECOLONIZATION

After being engaged in the Portuguese colonial issue, the United Nations increased its initiatives with the beginning of the war in Angola and, later on, on the eve of independence. Without disregard for other deciding factors, I intend to study the impact of the United Nations activities in the independence of Portuguese colonies. The core of the article will address the period between the overthrow of the Portuguese regime after the 25 April and the admission of Angola, in December 1976, as United Nations member state. First, the study will address the United Nations willingness to take part in the decolonization process and the refusal of its involvement by Portugal and the national liberation movements. Next, will be studied the moment when the Portuguese government decided to request the United Nations intervention and was confronted with the Secretary-General Kurt Waldheim hesitations to become involved in Timor and Angola. Underlying the article is the attempt to counter the prevailing idea that the United Nations did not play any role in the Portuguese decolonization.

Keywords: United Nations; Portugal; Portuguese Colonies; Self-determination; Independence
DE LA "FAIBLE PRÉSENCE"

AU FAIT ACCOMPLI: L'ORGANISATION DES NATIONS UNIES ET LA DÉCOLONISATION PORTUGAISE

En s'impliquant dans la question coloniale portugaise, l'Organisation des Nations Unies a intensifié ses initiatives avec le début de la guerre en Angola et, plus tard, à la veille de la décolonisation. Sans vouloir nier l'importance d'autres facteurs, nous souhaitons étudier l'impact des actions développées par les Nations Unies dans l'indépendance des colonies portugaises. Le noyau central de l'article sera constitué de l'intervalle entre le changement de régime au Portugal avec le 25 avril et l'admission de l'Angola en décembre 1976 en tant que membre de l'Organisation. L'analyse se référera d'abord à l'intérêt des Nations Unies à participer au processus de décolonisation et au refus de sa contribution par le Portugal et les mouvements de libération. Le deuxième moment nous renverra à la période où le gouvernement portugais a commencé à demander l'intervention de l'Organisation et où il a été confronté aux craintes du Secrétaire général, Kurt Waldheim, quant à un éventuel compromis avec la situation au Timor et en Angola. Sous-jacent à cet article sera la tentative de démystifier la compréhension qui a été propagée selon laquelle les Nations Unies n'ont pas participé au processus de décolonisation portugaise.

Mots-clés: Organisation des $\mathrm{Na}$ tions Unies; Portugal; Colonies Portugaises; Autodétermination; Indépendance 
O processo de descolonização português tem vindo a ser crescentemente valorizado enquanto objeto de estudo. A afirmação de José Medeiros Ferreira em 1994 segundo a qual «Escrever sobre a descolonização é operar num domínio ainda sacralizado da história nacional» ${ }^{1}$ já não se aplica, uma vez que se verificou uma consolidaçáo da bibliografia analítica sobre a temática. Pese embora a comparação com os demais aspetos da história de Portugal possa demostrar que a descolonização continua a ser estudada por uma minoria a produção de literatura científica e memorialística tem-se consolidado. A história da descolonização portuguesa tem gerado obras genéricas e de síntese, que detalham os desenvolvimentos ocorridos até 1975 . Outra tendência destaca a intervenção de alguns países, em particular dos Estados Unidos da América e do Reino Unido, no processo. O comportamento dos protagonistas da descolonizaçáo tem de igual modo merecido atenção no âmbito de estudos biográficos. Em alternativa algumas das mais recentes abordagens que de alguma forma tocam o tema têm optado por examinar a vertente dos movimentos de libertação, procurando demonstrar como desenvolveram esforços para atingir os seus objetivos.

Esta literatura distingue-se pelo estudo de algumas problemáticas, com os autores a avançarem diferentes interpretaçóes para o fenómeno da descolonização portuguesa. A título de exemplo, existem aqueles que entendem que foi a metrópole a conceder a independência às colónias, ou seja, o centro a dispensar a periferia ${ }^{2}$. Outros argumentam que a periferia teve um papel fundamental, tendo sido os movimentos de libertaçáo a conquistarem a independência. Existem também os que afirmam que a independência das colónias portuguesas esteve intimamente associada ao desenrolar do processo de transição para a democracia em Portugal ${ }^{3}$. Uma interpretação bastante difundida conjuga fatores como a situação militar nas colónias, a existência de pressôes internacionais e o surgimento de opiniốes favoráveis à independência entre os membros do novo governo português ${ }^{4}$. Numa perspetiva diferente, o debate tem enfatizado que a utilização do termo descolonização enquanto política adotada ativamente pela potência colonial tem uma aplicação problemática no caso português, uma vez que as colónias se teriam tornado independentes de forma não planeada ${ }^{5}$.

Estas interpretações, embora contribuam para uma melhor compreensão da temática, apresentam limitaçóes que evidenciam que a descolonização portuguesa necessita de investigaçôes mais aprofundadas para se responder às questóes ainda em aberto. Para ilustrar esta afirmação basta referir a forma como a relevância das pressões internacionais na descolonização portuguesa tem sido estudada. Existem estudos que quase

\footnotetext{
${ }^{1}$ FERREIRA, José Medeiros - “A Descolonização: Seu Processo e Consequências”. In MATTOSO, José - História de Portugal: Portugal em Transe (1974-1985). Vol. VIII. Lisboa: Editorial Estampa, 1994. p. 54.

${ }^{2}$ PINTO, António Costa; LLOYD-JONES, Stewart - The Last Empire. Thirty Years of Portuguese Decolonization. Bristol: Intellect, 2003. p. 21.

${ }^{3}$ PIMENTA, Fernando - “Descolonização Portuguesa. Estado da Arte, Problemáticas e Fontes”. Estudos do Século XX. Coimbra: IUC. N. ${ }^{\circ} 1$ (2011) p. 153-157.

${ }^{4}$ FERREIRA, José Medeiros - Ob. Cit. p. 58.

${ }^{5}$ MACQUEEN, Norrie - "Portugal". In THOMAS, Martin; THOMPSON, Andrew - The Oxford Handbook of the Ends of Empire. Reino Unido: Oxford University Press, 2015. p. 1.
} 
não contemplam a dimensão internacional, enquanto outros referem-na de maneira incompleta $^{6}$. Na maior parte dos casos estudam-se as pressóes exercidas sobre Portugal para a independência das colónias e a influência da Guerra Fria na descolonização de Angola, onde o processo foi marcado pela intervenção das grandes potências.

O papel da Organização das Naçóes Unidas (ONU) tem sido pouco referido quando se equaciona a dimensão internacional. O envolvimento das Naçôes Unidas (NU) na questão colonial portuguesa é analisado sobretudo no que se refere ao período entre 1955-1974, destacando-se o diferendo entre Portugal e a Organização. Para o período pós-25 de Abril são escassas as referências, limitando-se a declaraçóes segundo as quais o processo de descolonização foi «...ponto de honra das NU e outras instituiçôes internacionais»" ou que "...a ação da ONU sobre o poder político português, no respeitante à questão colonial, começa logo após a investidura do general Spínola como presidente da República» ${ }^{8}$. Tais afirmaçôes não são aprofundadas, sendo superficiais e carecendo da devida problematização. O pouco que se tem escrito sobre a questão não está isento de generalizaçôes e de afirmações pouco fundamentadas. Um exemplo é a ideia que defende que a Organização não participou no processo de descolonização por o governo português ter recusado essa possibilidade? .

Podemos concluir que até ao momento não existe um estudo satisfatório sobre o papel desempenhado pelas NU no processo de descolonização português. Esta é indiscutivelmente uma das linhas de investigação a ser aprofundada para se avançar o conhecimento quanto à independência das colónias portuguesas. Este artigo tem como objetivo centrar-se nesse tema, com recurso a fontes ainda náo exploradas. O núcleo central do artigo será constituído pelo período entre o 25 de Abril e a admissão de Angola, em dezembro de 1976, como membro da Organização. Num primeiro momento, analisaremos o interesse das NU em participar no processo de descolonizaçáo e a recusa do seu envolvimento pelas partes interessadas. Em seguida, abordaremos o período em que o governo português passou a solicitar a intervenção da Organização e em que foi confrontado com a rejeiçáo do secretário-geral (SG). A argumentação subjacente ao artigo procurará evidenciar que as NU não estiveram ausentes da descolonização portuguesa, uma vez que influenciaram o processo.

\section{"Uma Débil Presença”}

No seguimento do 25 de Abril, após 13 anos de um conflito marcado por diferentes níveis de intensidade, a questão da descolonização ganhou centralidade na política portuguesa. A soluçáo a implementar em relação às colónias não foi no entanto claramente definida no programa do Movimento das Forças Armadas (MFA), que propôs objetivos vagos, como a procura de uma soluçáo política, a realização de um debate nacional e a promoçáo da paz. No momento da redação do documento, o

\footnotetext{
${ }^{6}$ MACQUEEN, Norrie - "Portugal”... p. 1-20.

${ }^{7}$ PINTO, António Costa - A Cena Internacional, a Guerra Colonial e a Descolonização. 1961-1975. Lisboa: Livros Horizonte, 2001. p. 66.

${ }^{8}$ FERREIRA, José Medeiros - Ob. Cit. p. 56.

${ }^{9}$ Idem, p. 59.
} 
general António de Spínola tinha conseguido que não houvesse referências ao direito à autodeterminação ${ }^{10}$. Defendendo que primeiramente se implementasse um cessar-fogo e que a decisão quanto ao futuro das colónias obedecesse a um calendário alargado, Spínola era partidário de um modelo federalista. Considerava que a autodeterminaçáo não poderia conduzir necessariamente à independência e que as populaçóes deveriam ter a oportunidade de exprimir-se através de referendos ${ }^{11}$. Prevendo a consciencialização e o esclarecimento das populaçóes como condição prévia a qualquer ação, Spínola rejeitou a ideia da realização de negociaçóes imediatas com os movimentos de libertação.

O programa do I Governo Provisório não colocou entraves ao modelo spinolista, significando que num primeiro momento prevaleceu a tendência para se evitar um compromisso explícito com a autodeterminação e a independência ${ }^{12}$. Mas, rapidamente assistiu-se ao falhanço do projeto concebido por Spínola, o que poderá ser atribuído a uma conjugação de fatores. Desde logo, temos a divergência de opiniōes entre Spínola e o MFA, sendo que o último defendia uma rápida descolonização, com negociaçóes imediatas para a transferência do poder ${ }^{13}$. Por outro lado, surgiram na sociedade portuguesa, nomeadamente entre os partidos políticos, outros entendimentos quanto ao modelo e ao ritmo da descolonização, que propunham o fim imediato da guerra, a abertura de negociações com os movimentos de libertação e o reconhecimento do direito à autodeterminação ${ }^{14}$. Os movimentos de libertação igualmente exprimiram a sua discordância quanto a Spínola, opondo-se ao cessar-fogo e, em alguns casos, redobrando as suas atividades militares ${ }^{15}$. A somar a estes fatores, as tropas portuguesas que estavam nos teatros das operaçóes, como davam primazia ao fim do conflito armado, crescentemente demonstravam defender a independência das colónias em detrimento de outras soluçóes.

Para a não implementação do modelo spinolista terá igualmente contribuído as pressóes internacionais, não somente dos aliados portugueses e de outros países, mas também de organizações internacionais como a ONU e a Organização de Unidade Africana (OUA) ${ }^{16}$. Efetivamente, com as reticências portuguesas a motivarem desconfianças, as NU desencadearam iniciativas para assegurar que o modelo a implementar

\footnotetext{
${ }^{10}$ RODRIGUES, Luís Nuno - Spinola: Biografia. Lisboa: Esfera dos Livros, 2010.

${ }^{11}$ Arquivo Histórico Diplomático (AHD), Fundo Política e Organismos Internacionais (POI), Assembleia-Geral (AG), Mç. POI 699, Colonialismo: Generalidades, Apontamento Elaborado por José Maria Aleixo, Datado de Junho de 1974: "As Resoluçóes dos Órgáos da ONU e o Problema dos Territórios Ultramarinos Portugueses: Uma Tentativa de Interpretação", p. 16-17, 29-30.

${ }^{12}$ RUIVO, Francisco Beirão - Spinola e a Revolução. Do 25 de Abril ao 11 de Março de 1975. Lisboa: Bertrand Editora, 2014. p. 179-180.

${ }^{13}$ REIS, Bruno Cardoso - "Visôes das Forças Políticas Portuguesas sobre o Fim do Império, Dois Planos em Confronto e uma Política Exemplar de Descolonizaçấo (1974-1975)”. In ROSAS, Fernando; MACHAQUeIRO, Mário; OliVEIRA, Pedro Aires - O Adeus ao Império: 40 Anos de Descolonização Portuguesa. Lisboa: Veja, 2015. p. 95.

${ }^{14}$ Idem, p. 85-94.

${ }^{15}$ RODRIGUES, Luís Nuno - Spinola...p. 358.

${ }^{16}$ RODRIGUES, Luís Nuno - Marechal Costa Gomes. No Centro da Tempestade. Lisboa: A Esfera dos Livros, 2008. p. 149; OLIVEIRA, Pedro Aires - "A Descolonização Portuguesa: O Puzzle Internacional”. In ROSAS, Fernando; MACHAQUEIRO, Mário; OLIVEIRA, Pedro Aires - O Adeus ao Império: 40 Anos de Descolonização Portuguesa. Lisboa: Veja, 2015. p. 60-77.
} 
não se afastasse dos pressupostos que defendiam. Como explicar esse envolvimento da ONU? Pensamos poder atribuí-lo à instigação da OUA, da maioria afro-asiática e dos movimentos de libertação, que solicitaram à Organização que mantivesse a vigilância sobre Portugal. Havendo a expectativa que a mudança de regime em Portugal conduzisse à independência imediata das colónias, a ação da ONU revelou-se particularmente intensa durante o mês de maio. Para conhecer a posição portuguesa, um apelo à clarificação foi lançado pelo SG Kurt Waldheim, que enviou um emissário especial, Hans Janitschek, líder da Internacional Socialista, a Lisboa para conversaçóes com representantes portugueses ${ }^{17}$.

As iniciativas das NU ganharam maior atualidade com a investidura de António de Spínola como presidente da República (15 de maio), quando Kurt Waldheim entregou uma nota à representação portuguesa apelando à autodeterminação, que foi interpretada como sinónimo de independência, e indicando que as negociaçóes deveriam ter como interlocutores os movimentos de libertação ${ }^{18}$. Numa declaração publicada pelo Comité de Descolonização, as NU ressaltaram o facto de as afirmaçóes do governo português não estarem em conformidade com as suas resoluçóes e voltaram a exigir o reconhecimento imediato do direito das colónias à autodeterminação e à independência, a adoção de medidas concretas para a descolonização e o início de negociações com os movimentos de libertação reconhecidos pela OUA ${ }^{19}$. Disponibilizando-se a ajudar no processo de descolonização, Kurt Waldheim chamou posteriormente a atenção num comunicado para a necessidade de implementar as resoluçóes das NU e o consequente reconhecimento por Portugal do direito à autodeterminação e à independência ${ }^{20}$.

Estando sob o efeito destas e de outras pressóes, o governo português contrariou a posição de Spínola quanto aos contactos com os movimentos de libertação, iniciando ainda em maio conversaçóes preliminares com o Partido Africano para a Independência da Guiné e Cabo Verde (PAIGC) em Dakar e em Londres. Não pretendendo fazer concessões, o movimento solicitou o reconhecimento da proclamaçáo unilateral de independência da Guiné-Bissau e do direito de Cabo Verde a tornar-se independente. O PAIGC utilizou ativamente as NU para condicionar Portugal, designadamente com ameaças de que tinha a intenção de solicitar a admissão da Guiné-Bissau na Organização ${ }^{21}$. As NU foram constantemente informadas sobre o desenrolar das conversações e o SG realizou inúmeras reuniōes individualmente com emissários portugueses e com representantes do PAIGC. Nesses encontros, a situação da Guiné-Bissau foi enquadrada pela Organização num contexto diferente do das restantes colónias portuguesas por se considerar que se tratava de um Estado com parte do

\footnotetext{
${ }^{17}$ RODRIGUES, Luís Nuno - “António de Spínola e o Contexto Internacional da Descolonizaçáo”. In REZOLA, Maria Inácia; OLIVEIRA, Pedro Aires - O Longo Curso: Estudos em Homenagem a José Medeiros Ferreira. Lisboa: Tinta-da-China. p. 575-601. p. 581.

${ }^{18}$ FERREIRA, José Medeiros - Ob. Cit. p. 57.

${ }^{19}$ SANTOS, Aurora Almada e - O Comité de Descolonização da Organização das Naçóes Unidas e os Movimentos de Libertação das Colónias Portuguesas: 1961-1976. Lisboa: Texto Policopiado, 2009. p. 95

${ }^{20}$ RODRIGUES, Luís Nuno - “António de Spínola...”. p. 581.

${ }^{21}$ AHD, Fundo POI, AG, Mç. POI 699, Colonialismo: Estatuto de Observador Permanente junto da ONU, Carta do Ministro dos Negócios Estrangeiros (MNE) para o Director do Gabinete dos Negócios Políticos do Ministério da Coordenação Inter-Territorial, Datada de 5 de Julho de 1974, p. 1-2.
} 
território ocupado por outro país. Como reconhecido pelo governo português, esse enquadramento secundarizou a necessidade de consultar as populaçóes e legitimou o PAIGC como o único interlocutor das negociações ${ }^{22}$.

Pressionado pelos militares que estavam em Moçambique, Portugal iniciou igualmente encontros exploratórios com a Frente de Libertação de Moçambique (FRELIMO) em Lusaca, no mês de junho. A FRELIMO exigiu o reconhecimento da independência de Moçambique, a aceitação do movimento como o único representante do território e a transferência da soberania ${ }^{23}$. Tendo Portugal visado primeiramente alcançar o cessar-fogo, a ideia da transferência dos poderes foi rejeitada, propondo-se em troca um calendário que incluía um referendo. Opondo-se ao cessar-fogo e intensificando as suas açóes militares, a FRELIMO recorreu ao SG para resolver o impasse. Apoiando incondicionalmente a FRELIMO, tanto mais que não respondera a um telegrama da Frente Comum de Moçambique a solicitar um referendo, o SG questionou sobre a possibilidade da realização de uma eleição sob a supervisão das $\mathrm{NU}^{24}$. Com o apoio da Zâmbia e da Tanzânia, a FRELIMO indicou que esperava que o SG contribuísse para a retoma das negociaçôes, mas recusou a hipótese de as NU servirem como mediadoras ${ }^{25}$. Para o movimento, uma eventual participação da ONU deveria ser solicitada por ambas as partes e unicamente após ter sido alcançado um acordo ${ }^{26}$.

Dado que as conversações com o PAIGC e a FRELIMO foram inconclusivas, a Organização exigiu continuamente um maior esclarecimento, confrontando o governo português com as suas objeçóes ${ }^{27}$. Com o anúncio da visita de Mário Soares, ministro dos Negócios Estrangeiros, à sede das NU, o SG assumiu como objetivo pessoal pressionar o governo português para que realizasse negociaçóes diretas com os movimentos de libertação ${ }^{28}$. No encontro com o SG em junho, Mário Soares, indicando ser favorável à independência imediata, ressaltou contudo que as dificuldades políticas internas em Portugal não permitiam no momento a concretização desse objetivo ${ }^{29}$. Para que exercesse influência sobre as autoridades portuguesas e convencesse alguns setores da necessidade da descolonização, Mário Soares convidou o SG a se deslocar a Lisboa. Como indicado pelo próprio, Soares pretendia que a visita do SG resultasse na alteração da posição de

${ }^{22}$ AHD, Fundo POI, AG, Mç. POI 700, Eventual Declaração de Independência da Guiné pelo PAIGC, Apontamento Elaborado por Sacadura Cabral, do MNE, Datado de 12 de Junho de 1974: "Consideraçôes Gerais sobre o Problema da Autodeterminação dos Territórios Ultramarinos Portugueses", p. 3.

${ }^{23}$ United Nations Archives Record Management Section (UNARMS), S-0904-0017-04, Country Files of the Secretary-General (SG) Kurt Waldheim, Guinea-Bissau, Notes on a Meeting between the SG and the Minister of Foreign Affairs of Portugal, Saturday, 22 June 1974, 3:30 p.m., p. 3.

${ }^{24}$ UNARMS, S-0987-0004-05, SG Trips, Portugal, London, Bucharest and New York, 13 May-23 Aug 1974, Notes of a Meeting Held in the Office of the SG, 23 July 1974, p. 1-4.

${ }^{25} \mathrm{Ibidem}$.

${ }^{26}$ Ibidem.

${ }^{27}$ Pelas implicaçôes que poderia ter para a imagem do país, uma forma adicional de pressão das NU resultou da ação da comissáo de inquérito estabelecida em 1973 para analisar os massacres de Wiriyamu, em Moçambique. FERREIRA, José Medeiros - Ob. Cit. p. 119.

${ }^{28}$ UNARMS, S-0984-0001-01, SG Meetings, Confidential Notes and Minutes, 26 Dec 1973-24 May 1974, Notes on a Meeting Held in the SG Office on Thursday, 16 May 1974, 12:30 p.m., p. 1.

${ }^{29}$ UNARMS, S-0984-0001-04, SG Meetings, Under-Secretaries-General and Assistant Secretaries-General Meetings, 9 Jan 1974-27 Aug 1975, Note on the SG Meeting with the Under-Secretaries General and Assistant Secretaries-General on Wednesday, 26 June 1974, 10 a.m., p. 3. 
Spínola, a cuja intransigência atribuía o falhanço das primeiras reunióes com o PAIGC $^{30}$. Tendo uma outra reunião, ocorrida em junho, também se revelado inconclusiva, as conversaçóes com o PAIGC foram condicionadas pelas exigências do general quanto à realização de um referendo e à definição de um período transitório. Estas questôes somente foram ultrapassadas após a decisão tomada por uma assembleia do MFA na Guiné-Bissau, que reconheceu a legitimidade do PAIGC enquanto representante do povo guineense e exigiu o recomeço das negociaçóes com o movimento.

Tendo a Guiné-Bissau solicitado a admissão como membro da ONU, a posse do II Governo Provisório (18 de julho), resultando num maior envolvimento do MFA na questáo da descolonização, produziu o aceleramento do processo ${ }^{31}$. Spínola acabou por fazer concessóes, publicando a Lei 7/74, de 26 de julho, que reconheceu o direito à autodeterminação e à independência das colónias. De forma adicional, Portugal reavaliou a sua posição relativamente às NU, ultrapassando a rejeição que o Estado Novo sempre manifestara quanto à competência da Organização para analisar a sua política colonial ${ }^{32}$. Ao ter havido uma adequação formal da política portuguesa aos princípios das NU, o SG realizou em agosto a visita a Lisboa, o que tem sido considerado uma etapa relevante nas pressóes internacionais para a aceleração da descolonização ${ }^{33}$. Previamente à visita, os movimentos de libertação tentaram assegurar, com o envio de emissários e de telegramas, que o SG estivesse consciente das suas exigências ${ }^{34}$. $\mathrm{Na}$ agenda das conversaçóes foi previsto um item sobre o eventual envolvimento das NU nas negociaçóes enquanto garante do cessar-fogo, mediador, fiscalizador da manifestação da vontade das populaçóes e avalizador dos acordos de independência ${ }^{35}$.

Em Lisboa, o SG explicou a posição das NU e da OUA relativamente aos territórios portugueses, aconselhando o reconhecimento imediato da independência da Guiné- Bissau e a procura de soluçóes para as outras colónias. No comunicado publicado após as conversaçóes, Portugal assumiu o compromisso de respeitar as resoluçóes das NU e de aplicar a Lei 7/74, reforçou o reconhecimento do direito à autodeterminação e à independência e garantiu que respeitaria a unidade e a integridade territorial das colónias $^{36}$. Decorrente do compromisso foram retomadas as negociaçóes com o PAIGC, o que conduziu à assinatura do Acordo de Argel em agosto. Quase em simultâneo, por ocasião da discussão do pedido de admissão da Guiné-Bissau como Estado membro, a ONU voltou a vincar a sua posição. A Organização apelou a negociaçóes com os movimentos de libertaçáo, entendendo que os poderes deveriam ser-lhes transmitidos

${ }^{30}$ FERREIRA, José Medeiros - Ob. Cit. p. 60.

${ }^{31}$ RUIVO, Francisco Beirão - Ob. Cit. p. 197.

${ }^{32}$ SANTOS, Aurora Almada e - Ob. Cit. p. 96.

${ }^{33}$ FERREIRA, José Medeiros - Ob. Cit. p. 121.

${ }^{34}$ A título de exemplo temos o telegrama do PAIGC ao SG. Cf. UNARMS, S-0904-0017-04, Country Files of the SG Kurt Waldheim, Guinea-Bissau, Telegrama de Aristides Pereira, SG do PAIGC, para Kurt Waldheim, Datado de 27 de Julho de 1974, p. 1.

${ }^{35}$ Não foi possível confirmar se o item foi discutido. AHD, Fundo POI, AG, Mç. POI 705, Visita do SG da ONU a Portugal, Agenda para as Conversas com o SG das NU, p. 1.

${ }^{36}$ Aquando da visita do SG, os representantes portugueses solicitaram que o relatório da comissão de inquérito sobre os massacres em Moçambique não tivesse qualquer seguimento. Cf. $\mathrm{AHD}$, Fundo POI, AG, Mç. POI 699, Campanha do Times contra Portugal: Massacres Moçambique, Telegrama da Missão de Portugal na ONU para o MNE, Datado de 20 de Novembro de 1974, p. 1-2. 
sem referendos ${ }^{37}$. O facto de ter rejeitado eventuais referendos estava em concordância com as opinióes dos movimentos de libertação e de países africanos, que tinham informado o SG que a hipótese era inaceitável ${ }^{38}$.

Não obstante estes desenvolvimentos, Spínola procurou manter o controlo sobre o processo de descolonização, ensaiando algumas iniciativas nesse sentido. Em agosto, apresentou um plano para Angola que deveria ser concretizado em várias fases e num período de três anos ${ }^{39}$. Do plano constavam o cessar-fogo com os movimentos de libertação, a criação de um governo provisório de coligação, a realização de eleiçóes para uma Assembleia Constituinte e uma Assembleia Legislativa e o envolvimento da ONU no processo, com o envio de observadores para acompanharem a consulta popular ${ }^{40}$. Outra iniciativa de Spínola consistiu na criação da Comissão Nacional de Descolonização, que foi mandatada a intensificar e coordenar o planeamento do processo de descolonização ${ }^{41}$. A Comissão ficou sob a sua alçada, cabendo ao general tomar decisóes sobre eventuais problemas que surgissem e coordenar todos os órgáos do governo envolvidos na descolonização ${ }^{42}$.

Com os acontecimentos a contrariarem as intenções de Spínola, no seguimento do Acordo de Argel o governo português reconheceu em setembro a República da Guiné-Bissau como Estado independente. Deste modo, ficou implicitamente estabelecido que a descolonização deveria ter por base negociaçóes diretas com os movimentos de libertação, sem consultas populares. Ainda assim, os representantes portugueses continuaram a demonstrar não ter uma posição inequívoca relativamente à independência dos restantes territórios. Na sequência da retoma das negociaçóes com a FRELIMO, Spínola insistiu que os moçambicanos tivessem direito a escolher o seu regime político, num processo supervisionado por observadores internacionais ${ }^{43}$. Com o MFA a pressionar para que houvesse resultados imediatos, em setembro o governo português assinou o Acordo de Lusaca, que definiu as condiçóes para a independência de Moçambique. Tendo havido uma tentativa de revolta, a FRELIMO denunciou a situação à ONU, atribuindo a ação do governo português para reprimir a rebelião à circunstância do movimento ter invocado as garantias dadas ao SG em Lisboa ${ }^{44}$.

Entretanto, devido ao diferendo que vinha mantendo com o MFA, verificou-se a substituição de Spínola por Francisco Costa Gomes enquanto presidente da República. Assumindo a descolonização como prioridade, Costa Gomes, que inicialmente fora partidário do modelo spinolista, afirmou no entanto que o processo não deveria ser

\footnotetext{
${ }^{37}$ SANTOS, Aurora Almada e - Ob. Cit. p. 97.

${ }^{38}$ UNARMS, S-0904-0069-18, SG Kurt Waldheim, Mozambique, 28 Jun 1973-20 Dec 1976, Memorando de Tang Ming-Chao, Subsecretário-Geral para os Assuntos Politicos e Descolonização, para George Henning, Assistente Executivo do SG, Datado de 3 de Julho de 1974, p. 1.

${ }^{39}$ PIMENTA, Fernando Tavares - Angola, Os Brancos e a Independência. 2a Edição. Porto: Edições Afrontamento, 2016. p. 372.

${ }^{40}$ Ibidem.

${ }^{41}$ RODRIGUES, Luís Nuno - Marechal Costa Gomes...p. 184.

${ }^{42}$ RODRIGUES, Luís Nuno - Spinola...p. 462.

${ }^{43}$ Idem. p. 449.

${ }^{44}$ UNARMS, S-0904-0030-01, Country Files of the SG Kurt Waldheim, Mozambique, Notes of a Meeting Held in the SG Office, on 4 October 1974, p. 1-2.
} 
conduzido segundo esquemas rígidos e predeterminados ${ }^{45}$. Defendeu o respeito pelos interesses das populaçôes e a realização de consultas populares em Cabo Verde, São Tomé e Príncipe e Timor. Tendo contribuído, em associação com outros elementos, para o falhanço do projeto federalista de António Spínola, as pressóes das NU explicam também em parte o desvio em relação aos objetivos de Costa Gomes e a aplicação aos territórios onde não tinha havido luta armada de critérios semelhantes aos utilizados para a Guiné-Bissau, Moçambique e Angola ${ }^{46}$.

No Acordo de Argel foram aprovadas disposiçóes relativas a Cabo Verde, considerando-se que a sua população tinha direito à autodeterminação e à independência. Ainda assim, as negociaçôes para a independência de Cabo Verde foram conduzidas de forma separada das da Guiné-Bissau, devido às objeçôes levantadas por Portugal quanto à associação que o PAIGC pretendia estabelecer entre os dois territórios ${ }^{47}$. O PAIGC desenvolveu iniciativas junto da ONU e em particular do SG para chamar a atenção para as condiçóes de vida nas ilhas, alegando a morosidade na descolonização e o não cumprimento por Portugal do Acordo de Argel $^{48}$. Em setembro, comunicou a ocorrência de incidentes em São Vicente, acusando Portugal de ter disparado contra a população e de ter reforçado a presença militar ${ }^{49}$. Tendo tido a preocupação de continuar a explicitar publicamente a aceitação do direito à autodeterminação e à independência, nomeadamente aquando do discurso de Costa Gomes na Assembleia-Geral (AG) da ONU, o governo português apresentou em dezembro o Estatuto Orgânico para Cabo Verde, que previa a eleição de uma assembleia constituinte com poderes para determinar o futuro político do arquipélago ${ }^{50}$. De forma a acelerar a independência, o PAIGC convidou as NU a enviar uma missão ao território, o que teve lugar entre fevereiro e março de 1975. A missão de visita concluiu que a populaçáo estava determinada a tornar-se independente e a estabelecer uma união com a Guiné-Bissau sob a liderança do PAIGC, considerado como o seu único representante ${ }^{51}$.

Solução idêntica à de Cabo Verde foi adotada quanto a São Tomé e Príncipe, para cuja descolonização tem sido considerado que a visita do SG, Kurt Waldheim, a Lisboa teve um papel fundamental ${ }^{52}$. Com efeito, no seguimento da visita o governo português reconheceu o direito do povo são-tomense à autodeterminação e à independência. Os pronunciamentos das NU, em conjunto com a decisão adotada pelos militares portugueses presentes no território, possibilitaram a legitimação do Movimento de Libertação de São Tomé e Príncipe (MLSTP) como representante das populaçóes e interlocutor das negociaçóes com Portugal. Sendo acompanhadas de perto

\footnotetext{
${ }^{45}$ RODRIGUES, Luís Nuno - Marechal Costa Gomes...p. 182.

${ }^{46}$ MACQUEEN, Norrie - Ob. cit. p. 12.

${ }^{47}$ AHD, Fundo POI, AG, Mç. POI 699, Colonialismo: Generalidades, Apontamento Elaborado por Luís Crucho de Almeida, do MNE, Datado de Julho de 1974: "Comunicação de Informaçóes sobre os Territórios Não Autónomos nos Termos do Artigo 73 e) da Carta”, p. 5-6.

${ }^{48}$ AHD, Fundo POI, AG, Mç. POI 699, Descolonização de Cabo Verde, Telegrama da Missão de Portugal na ONU para o MNE, Datado de 22 de Outubro de 1974, p. 1.

${ }^{49}$ UNARMS, S-0904-0017-04, Country Files of the SG Kurt Waldheim, Guinea-Bissau, Tradução não Oficial do Telegrama Enviado por Aristides Pereira, SG do PAIGC, a Kurt Waldheim [Setembro de 1974], p. 1.

${ }^{50}$ RODRIGUES, Luís Nuno - Marechal Costa Gomes... p. 186; FERREIRA, José Medeiros - Ob. cit. p. 62.

${ }^{51}$ SANTOS, Aurora Almada e - Ob. Cit. p. 100-101.

${ }^{52}$ FERREIRA, José Medeiros - Ob. Cit. p. 63-64.
} 
pela Organização, a quem o governo português informou sobre os desenvolvimentos verificados, as negociaçóes relativas a São Tomé e Príncipe conduziram à assinatura de um protocolo entre Portugal e o MLSTP ${ }^{53}$. Com a rejeição da realização de um referendo, foi contemplada a eleição de uma assembleia constituinte, que ficaria encarregue de conduzir o território à independência.

Que ilaçóes podem ser retiradas dos factos acima expostos? Desde logo, pode-se destacar que tanto os movimentos de libertaçáo como alguns setores do governo português recorreram às NU para utilizar a sua pressão como ferramenta de persuasão. Em alguns momentos, o SG e o general Spínola demonstraram o desejo que as NU interviessem diretamente no processo de descolonização. Estas intençôes não se concretizaram por o MFA e Costa Gomes terem entendido que um eventual envolvimento da Organização seria desprestigiante para o país e os movimentos de libertação não terem mostrado interesse nos seus bons ofícios ${ }^{54}$. Ainda assim, pensamos poder contrariar a ideia segundo a qual verificou-se "Uma Débil Presença" da ONU no processo de descolonização português ${ }^{55}$. A influência da Organização pode ser atestada pela circunstância de Portugal ter acabado por aceitar que a autodeterminaçáo fosse equivalente à independência, que os movimentos de libertação eram os únicos interlocutores das negociaçóes e que a realização de referendos não tinha cabimento.

\section{Fait Accompli}

Tendo as NU, com o voto unânime do Conselho de Segurança (CS), admitido Moçambique, Cabo Verde e São Tomé e Príncipe como estados membros, desde meados de 1975 foram as situações de Timor e de Angola a dominarem a sua atenção. No quadro da Lei 7/74, o governo português planeara que Timor alcançaria a independência em 1978, mas a situaçáo deteriorou-se rapidamente, com a ocorrência de conflitos armados entre diferentes grupos. Na iminência de uma guerra civil, Portugal solicitou o envolvimento pessoal do SG na descolonização de Timor, procurando a internacionalização da questão ${ }^{56}$. Organizaçôes timorenses, como a União Democrática de Timor (UDT), a Associação Popular Democrática Timorense (APODETI) e a Frente Revolucionária de Timor-Leste Independente (FRETILIN), tentaram igualmente envolver as NU na disputa, visando a legitimação das suas pretensóes.

Com o Comité de Descolonizaçáo a deslocar-se em junho a Lisboa, onde realizou um conjunto de reuniốes, o órgão exprimiu a esperança que fossem adoptadas medidas necessárias para permitir ao povo timorense alcançar a autodeterminação e a independência. Verificando-se as primeiras acçóes violentas, em agosto a UDT desencadeou um golpe militar e a FRETILIN assumiu o controlo sobre os quartéis militares. Alertado pelo governo português, o SG lançou um apelo à cessação das

${ }^{53}$ Idem, p. 64.

${ }^{54}$ Idem, p. 59.

${ }^{55}$ Ibidem.

${ }^{56}$ AHD, Fundo POI, AG, Mç. POI 740, Descolonização de Timor, Telegrama da Missão de Portugal na ONU para o MNE, Datado de 23 de Dezembro de 1975, p. 1. 
hostilidades, ao respeito pelas vidas humanas e ao início de negociaçôes ${ }^{57}$. Para ajudar na clarificação da situação e na restauração da ordem, Portugal entendeu propor a participação da ONU na criação de uma comissão de bons ofícios, na realização de uma intervenção multilateral humanitária e, posteriormente, na promoção de uma conferência entre as organizaçóes timorenses ${ }^{58}$. Face às propostas portuguesas, os conselheiros do SG entenderam que um eventual envolvimento das NU deveria resultar de um mandato oficial do CS e da AG, sendo que a Organização somente poderia ser útil em termos humanitários ${ }^{59}$.

Em novembro, realizaram-se conversaçôes em Roma entre o governo português e a Indonésia sobre o futuro de Timor, com ambas as partes a se comprometerem a manter uma cooperação estreita ${ }^{60}$. Com o aprofundamento das divergências, a FRETELIN proclamou a independência unilateral a 28 de novembro e a UDT e outras organizaçôes anunciaram a integração na Indonésia. Sem que Portugal tivesse reconhecido as declaraçóes, a IV Comissão analisou em dezembro a situação nas colónias portuguesas, com a questấo de Timor a ser o tema central. Antes de as NU terem concluído as deliberações, a Indonésia invadiu o território, numa ação que conduziu ao corte das relaçôes diplomáticas entre Portugal e o país ${ }^{61}$. Reconhecendo os poderes de Portugal enquanto potência administrante, a AG, na resolução 3485 (XXX), de 12 de dezembro, lamentou profundamente a invasão e solicitou a retirada das forças invasoras. Ainda que tivesse ficado estabelecido que o Comité de Descolonização deveria enviar uma missão de inquérito ao território, a resolução não foi demasiado penalizadora para a Indonésia. A linguagem empregue traduziu uma certa moderação, uma vez que a atuação do governo indonésio não foi condenada e não lhe foram impostas quaisquer exigências ${ }^{62}$. A explicação para a moderação reside na polarização das posiçôes entre os estados membros, por terem sido apresentados vários projectos de resoluçáo, acabando por ser aprovado um texto que fora sujeito a emendas que desvirtuaram algumas das suas afirmaçóes.

O governo português, que não dispunha de outras alternativas além do recurso às NU, desenvolveu esforços para que o CS adoptasse uma posição que salvaguardasse os princípios da autodeterminação e da não-agressão ${ }^{63}$. Solicitou ainda a assistência do SG para a libertação dos soldados portugueses capturados pela UDT, tendo havido

\footnotetext{
${ }^{57}$ UNARMS, S-0904-0039-02, Country Files of the SG Kurt Waldheim, Timor, Press Release SG/ SM/2236, 26 August 1975, p. 1.

${ }^{58}$ UNARMS, S-0904-0039-02, Country Files of the SG Kurt Waldheim, Timor, Note on Meeting with Mr. António Leal da Costa Lobo, Chargé d'Affaires of Portugal, in Rafeeuddin Ahmed's Office, 11:30 a.m., on 3 September 1975, p. 1.

${ }^{59}$ UNARMS, S-0984-0001-04, SG Meetings, Under-Secretaries-General and Assistant SecretariesGeneral Meetings, 9 Jan 1974-27 Aug 1975, Note on the SG Meeting with the Under-Secretaries General and Assistant Secretaries-General, 27 August 1975, 10 a.m., p. 1.

${ }^{60}$ PINTO, António Costa - A Cena Internacional...p. 31.

${ }^{61}$ Ibidem.

${ }^{62} \mathrm{http}: / /$ www.un.org/en/sections/documents/general-assembly-resolutions/index.html.

${ }^{63}$ AHD, Fundo POI, AG, Mç. POI 740, Descolonização de Timor, Telegrama da Missão de Portugal na ONU para o MNE, Datado de 17 de Dezembro de 1975, p. 1-2.
} 
diligências do Secretariado nesse sentido ${ }^{64}$. No seguimento da convocação do CS, foi aprovada a 22 de dezembro a resoluçáo 384 (1975) que, dadas as divisôes havidas entre os afro-asiáticos e a insistência de alguns países em criticar Portugal, reprovou tanto o comportamento indonésio quanto o português. O texto deplorou a intervenção da Indonésia, solicitando novamente a retirada das suas forças, e lamentou que Portugal não tivesse desempenhado as suas funçôes de potência administrante ${ }^{65}$. Ao contrário do desejado pelos representantes portugueses, não ficou previsto o envolvimento das NU na supervisão do cumprimento pela Indonésia do pedido de retirada. A resolução determinou unicamente o envio de um representante especial do SG a Timor para examinar a situação no terreno e estabelecer contactos com as organizaçóes timorenses e os países interessados na questão.

Com a concordância do governo português, o SG em dezembro encarregou Vittorio Guicciardi, diretor do Gabinete das NU em Genebra, a empreender uma visita a Timor. O SG demonstrou possuir uma avaliação pouco realista da situação por acreditar que a Indonésia estava interessada em promover uma consulta às populaçóes e em fazer concessões $^{66}$. O envolvimento pessoal do SG pretendido pelo governo português náo se concretizou, tendo Kurt Waldheim se limitado a transmitir ao CS o relatório elaborado por Guicciardi. Com a análise do referido relatório, o CS adotou em abril de 1976 a resolução 389 (1976), que na sua substância não apresentava novidades. Foi novamente solicitado à Indonésia que retirasse as suas forças e o SG foi encarregue de pedir ao representante especial que continuasse a sua missão ${ }^{67}$. Tendo Kurt Waldheim sido igualmente mandatado a seguir a aplicação da resolução, a sua passividade provocou algum descontentamento, com a União Soviética a considerar que a Organização demonstrara a tendência para aceitar um Fait Accompli ${ }^{68}$. Sem que a Indonésia tivesse sido penalizada, Timor foi mantido na lista dos territórios não autónomos, ficando a questão em aberto uma vez que a independência não teve lugar.

A par de Timor, o problema angolano foi objeto de grande atenção nas NU, com representantes do governo português, dos movimentos de libertaçáo e da OUA a recorrerem constantemente à Organização. Tendo a Frente Nacional de Libertação de Angola (FNLA), o Movimento para a Libertação de Angola (MPLA) e a União Nacional para a Independência Total de Angola (UNITA), reconhecidos como interlocutores para as negociações, concordado com o cessar-fogo foi assinado, em janeiro de 1975, o Acordo de Alvor. Apresentando um modelo para a independência assente no entendimento entre os três movimentos, o Acordo estava em concordância com a visão de Costa Gomes, que pretendia uma política de consenso ${ }^{69}$. Aceitando de início uma plataforma de compromisso, os movimentos de libertação rapidamente

${ }^{64}$ UNARMS, S-0904-0030-01, Country Files of the SG Kurt Waldheim, Mozambique, Note for the File, Elaborado por Rafeeuddin Abmed, Datado de 27 de Dezembro de 1975, p. 1.

${ }^{65} \mathrm{http}: / /$ www.un.org/en/sc/documents/resolutions/.

${ }^{66}$ UNARMS, S-0904-0030-01, Country Files of the SG Kurt Waldheim, Mozambique, Notes on a Meeting between the SG and the Permanent Representative of Portugal, 8 January 1976, 1 p.m., p. 1.

${ }^{67} \mathrm{http}: / /$ www.un.org/en/sc/documents/resolutions/.

${ }^{68}$ UNARMS, S-0984-0001-08, SG Meetings, Minutes on Meetings, SG Kurt Waldheim, 24 Sept-17-Dec 1975, Meeting between the SG and Ambassador Malik, on 24 December 1975, 10 a.m., p. 1.

${ }^{69}$ RODRIGUES, Luís Nuno - Marechal Costa Gomes...p. 188. 
tentaram no entanto conquistar pontos estratégicos, favorecendo a internacionalização do conflito com a procura de apoios externos. Como solicitara para ser informado sobre os acontecimentos, o SG, a pedido do governo português, enviou em abril a Luanda um enviado pessoal, Abdulrahim Farah, subsecretário-geral para as Questóes Políticas Especiais, acompanhado por um representante da OUA, para conversaçóes ${ }^{70}$. Com Portugal a adotar uma posição de "neutralidade ativa" e temendo-se a declaração unilateral de independência por um dos movimentos, as NU exprimiram em junho a esperança de que se conseguisse uma solução para assegurar a unidade e a solidariedade.

Em agosto teve início a evacuação de um número indeterminado de pessoas ( $\mathrm{da}$ minoria branca e náo só) com destino a Portugal, através de uma ponte aérea estabelecida pelas autoridades portuguesas com a ajuda de outros países. Esta questáo mereceu a preocupação da ONU, motivando o envio de uma nota pelo Alto Comissariado para os Refugidos (ACNUR) ao $S G^{71}$. A posição do ACNUR foi a de que a Organização não deveria se envolver na evacuação, pois a situação legalmente não recaia no âmbito das suas competências, e que as ajudas deveriam ser canalizadas para o desenvolvimento de Angola ${ }^{72}$. Ainda assim, crescentemente várias agências da ONU participaram na assistência aos chamados "retornados", fornecendo-lhes víveres e bens materiais, nomeadamente em Luanda e Nova Lisboa. As consideraçôes políticas estiveram sempre subjacentes a esse envolvimento, dado o receio de que a Organizaçáo pudesse ser chamada a assumir responsabilidades numa escala superior aos seus recursos ${ }^{73}$.

Em virtude da perda do controlo sobre a situação e da existência no seio do V Governo Provisório de elementos com simpatia em relação à FNLA e à UNITA, Portugal tentou também, por sua vez, internacionalizar a questão angolana. Costa Gomes, em setembro, instruiu Almeida Santos, enquanto enviado especial, a questionar o SG sobre a possibilidade das NU, caso os desentendimentos entre os movimentos de libertação continuassem, assumirem a responsabilidade pelo território ${ }^{74}$. Tendo sido informado que tal cenário era impossível, o governo português acabou por suspender o Acordo de Alvor devido ao estado de guerra. Informando que pretendia organizar uma conferência para definir as modalidades para a transferência do poder em Angola, solicitou novamente em outubro o apoio do SG e do Comité de Descolonização para contornar as divergências entre os movimentos. Ao indicar que a situação dificilmente poderia ser resolvida no quadro da ONU, o SG remeteu a procura de soluçóes para a

\footnotetext{
${ }^{70}$ AHD, Fundo POI, AG, Mç. POI 741, Descolonização de Angola, Apontamento do MNE, Datado de 3 de Abril de 1975: "A Visita do Embaixador Abdulrahim Farah, como Representante do SG da ONU, a Luanda”, p. 2.

${ }^{71}$ UNARMS, S-0904-0033-06, Country Files of the SG Kurt Waldheim, Portugal-Portuguese Territories, Note pour le Secretaire Général (Préparée par le Haut-Commissariat des Nations Unies por les Réfugiés), Genève, le 15 Août 1975, p. 1.

${ }^{72}$ UNARMS, S-0984-0001-07, SG Meetings, Minutes on Meetings, SG Kurt Waldheim, 10 Jan-23 Sept 1975, Notes on a Meeting between the SG and Messrs. Homann-Herimberg and Opdahl (UNHCR), Held at Hilton Hotel Zurich, on 17 August at 10:30 am, p. 1.

${ }^{73}$ UNARMS, S-0984-0001-06, SG Meetings, Confidential Notes, SG Kurt Waldheim, 30 Dec 1975-19 Sept 1975, Nota para o SG, Datada de 13 de Setembro de 1975 e Elaborada por Abdulrahim Farah, p. 4.

${ }^{74}$ UNARMS, S-0904-0030-01, Country Files of the SG Kurt Waldheim, Mozambique, Minutes of a Meeting Held in the Office of the SG, on 24 September 1975, p. 1.
} 
OUA enquanto entidade regional ${ }^{75}$. Quando questionado por representantes da OUA sobre a eventualidade das NU participarem na restauração da paz, Kurt Waldheim voltou a indicar que qualquer iniciativa deveria partir dos países africanos ${ }^{76}$. Como os movimentos angolanos não solicitaram a intervenção das NU como mediadora, acabou por ser decidido que a OUA não proporia que a Organizaçáo analisasse a questáo antes da data prevista para a independência ${ }^{77}$.

Evitando comprometer-se, a atitude da ONU foi determinada pelo receio que a Organização fosse confrontada com uma situação semelhante à do Congo no início dos anos 60. Respondendo a pedidos de assistência militar, as NU tinham estado envolvidas numa tentativa para solucionar os problemas decorrentes da independência do Congo, o que teve custos assinaláveis para a Organização ${ }^{78}$. Pelas suas implicaçôes, a operação das NU no Congo esteve presente nas consideraçóes de Kurt Waldheim, condicionando as suas opçóes quanto a Angola ${ }^{79}$. Com medo que houvesse um "segundo Congo", o SG foi bastante cauteloso em salvaguardar a posição da ONU, exprimindo preocupação por a responsabilidade pela receção da ajuda humanitária a Angola ter sido atribuída ao MPLA ${ }^{80}$. O SG temia que a assistência da Organização fosse interpretada como um reconhecimento de facto do MPLA enquanto autoridade competente na matéria. Para evitar qualquer embaraço, Kurt Waldheim aconselhou o representante em Angola do Programa das NU para o Desenvolvimento (PNUD) a abandonar o território antes da declaração de independência, pois a sua presença poderia envolver politicamente a Organização no diferendo ${ }^{81}$.

Apesar da posição assumida, o SG manteve-se em contacto com o governo português e com representantes da OUA, esperando que fosse encontrada uma soluçáo antes da independência. A OUA manifestou ao SG ter grandes preocupaçóes, receando que a qualquer momento pudesse haver uma declaração unilateral de independência. $\mathrm{O}$ seu Conselho de Ministros e a sua Comissão de Defesa envolveram-se na questão, procurando nomeadamente determinar a necessidade do envio a Angola de uma força de manutenção da paz da ONU ${ }^{82}$. Uma vez que, além da resistência da ONU, os movimentos de libertação não estavam disponíveis para concertar posiçôes, os esforços da OUA não

${ }^{75}$ AHD, Fundo POI, AG, Mç. POI 750, Debate Geral, Apontamento Elaborado por Sacadura Cabral, Datado de 14 de Outubro de 1975: "Tópicos da Conversa do Ministro dos Negócios Estrangeiros de Portugal com o Secretário-Geral da ONU Realizada em Nova Iorque em 9 de Outubro de 1975”, p. 3.

${ }^{76}$ UNARMS, S-0972-0001-04, Organization of African Unity, SG Kurt Waldheim, 10 Jan-31 Dec 1975, Meeting with the SG of the Organization of African Unity, 10 October 1975, p. 1.

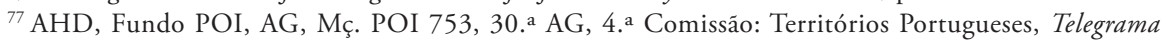
da Missão de Portugal na ONU para o MNE, Datado de 25 de Setembro de 1975, p. 1.

${ }^{78}$ KENT, John - America, the UN and Decolonization. Cold War Conflict in the Congo. Londres: Routledge, 2010.

${ }^{79}$ UNARMS, S-0904-0030-01, Country Files of the SG Kurt Waldheim, Mozambique, Memorando de Erik Suy, do Legal Counsel, para o SG, Datado de 2 de Setembro de 1975, p. 1-2.

${ }^{80}$ UNARMS, S-0904-0030-01, Country Files of the SG Kurt Waldheim, Mozambique, Notes of the SG to Abdulrahim Farah, Datada de 7 de Dezembro de 1975, p. 2.

${ }^{81}$ UNARMS, S-0984-0001-08, SG Meetings, Minutes on Meetings, SG Kurt Waldheim, 24 Sept-17 Dec 1975, Notes on the SG Meeting with Mr. Jaime Balcazar, UN Development Program Resident Representative in Angola, 6 November 1975, p. 2.

${ }^{82}$ UNARMS, S-0972-0001-04, Organization of African Unity, SG Kurt Waldheim, 10 Jan-31 Dec 1975, Note for the SG, Elaborado por Abdulrahim Farah, a 10 de Novembro de 1975, p. 1. 
produziram resultados. A 11 de novembro, o MPLA proclamou a República Popular de Angola e a FNLA e a UNITA instituíram a República Democrática de Angola. Sem que tivesse reconhecido qualquer dos governos devido a uma decisão do Conselho da Revolução, Portugal entregou ao SG o texto da declaração de independência, indicando que não tinha interesse numa eventual convocação do CS para debater a situaçáo ${ }^{83}$.

Prontificando-se unicamente a fornecer assistência técnica às populaçóes, independentemente do movimento que controlasse as áreas onde residiam, a ONU decidiu aguardar que a OUA assumisse a iniciativa não obstante as tentativas de alguns sectores do governo norte-americano para transformarem a Organização no principal fórum para se abordar o problema angolano ${ }^{84}$. Ainda em janeiro de 1976, o SG indicou estar à espera dos resultados de uma reunião em Addis-Abeba, após o que pretendia enviar apoio humanitário a Angola ${ }^{85}$. Sujeito a pressóes de vários países e ao que tudo indica da própria ONU, Portugal acabou por reconhecer em fevereiro a República Popular de Angola ${ }^{86}$. O reconhecimento por parte da ONU ocorreu aquando da aceitação em finais de 1976 do pedido de admissão apresentado pelo MPLA. Mesmo se anteriormente, em junho, as divisóes no CS tivessem impedido os passos necessários à admissão do país, em novembro foi decidido recomendar à $A G$ a aprovaçáo do pedido. Tendo-se recusado a comprometer-se com a situação que conduziu à guerra civil, com a aceitação de Angola enquanto Estado membro as NU voltaram uma vez mais a encontrar-se na posição de ter legitimado um Fait Accompli ${ }^{87}$.

Face ao exposto, voltamos à questão acima levantada sobre as ilaçóes a retirar quanto a estes acontecimentos? Consideramos que será seguro afirmar que, mesmo se as NU náo estiveram diretamente envolvidas nas questóes de Timor e de Angola, as suas ações não podem ser ignoradas. Como explicado, as razões da não participação direta das NU nos acontecimentos deveram-se aos receios do SG em comprometer-se com situações eventualmente difíceis de solucionar. As inúmeras reunióes realizadas em Nova Iorque em paralelo ao desenrolar dos acontecimentos no terreno tornaram ainda assim as NU num ator relevante. No fundo, foram responsáveis pela definição do enquadramento normativo, defendendo a independência, que deveria resultar na preservação da unidade nacional e da integridade territorial. Mesmo se esse enquadramento não foi aplicado na íntegra e se possa questionar a conduta das NU quanto à invasão de Timor e ao iniciar da guerra civil em Angola, o papel desempenhado pela Organização na descolonização portuguesa foi no entanto inquestionável.

\footnotetext{
${ }^{83}$ UNARMS, S-0904-0030-01, Country Files of the SG Kurt Waldheim, Mozambique, Notes on a Meeting between the SG and the Permanent Representative of Portugal to the UN, 12 November 1975, 5 p.m., p. 1.

${ }^{84}$ SCHNEIDMAN, Witney - Confronto em África: Washington e a Queda do Império Colonial Português. Lisboa: Tribuna da História, 2005. p. 280.

${ }^{85}$ UNARMS, S-0904-0030-01, Country Files of the SG Kurt Waldheim, Mozambique, Notes on a Meeting between the SG and the Permanent Representative of Portugal to the UN, 8 January 1976, 1 p.m., p. 1.

${ }^{86}$ RODRIGUES, Luís Nuno - Marechal Costa Gomes...p. 335.

${ }^{87}$ UNARMS, S-0984-0001-08, SG Meetings, Minutes on Meetings, SG Kurt Waldheim, 24 Sept-17 Dec 1975, Notes on a Meeting between the SG and the Permanent Representative of France to the UN, 8 December 1975, 1 p.m., p. 2.
} 


\section{Consideraçóes finais}

Faz sentido estudar a influência da ONU na descolonização portuguesa? Este artigo não pretende afirmar que esta dimensão da descolonização portuguesa deverá ser estudada de forma isolada. Pelo contrário, procurou-se dar um contributo para a consolidação das leituras que têm sido efetuadas sobre o tema, para que o envolvimento da ONU na descolonização portuguesa possa ser integrado de forma mais detalhada nas tentativas de compreensáo do processo que conduziu à independência das colónias. Entendendo que Portugal deveria realizar a descolonização total, a Organização contribuiu para a definição do modelo e do ritmo para solucionar a questão colonial portuguesa. A sua influência foi sentida designadamente na afirmação da necessidade da independência e da realização de negociaçóes diretas, com a transferência dos poderes sem referendos. Desempenhou igualmente um papel na identificação dos interlocutores para as negociaçóes, que solicitou que fossem as organizaçóes envolvidas na luta armada e que tinham sido previamente reconhecidas pela OUA.

Tendo havido especificidades próprias em relação a cada um dos territórios, podem ser destacados dois momentos distintos na forma como a Organização contribuiu para a descolonização portuguesa. Esses momentos foram o culminar de um processo que se desenrolou desde a admissão de Portugal como Estado membro das NU em finais de 1955 e testemunham a importância que a Organização assumiu no desmantelamento dos impérios coloniais europeus no pós-II Guerra Mundial. Com efeito, a ONU constituiu um dos principais fóruns de confrontação entre as potências coloniais e os opositores anti-coloniais, sendo que o caso português foi um exemplo paradigmático das inúmeras contradiçóes às quais a intervenção da Organização na autodeterminação dos povos colonizados esteve sujeita.

Fontes e Bibliografia

\section{Fontes}

Arquivo Histórico-Diplomático

Fundo Política e Organizaçóes Internacionais (POI)

Assembleia-Geral, Mç. POI 699, 700, 705, 740, 741, 750, 753.

Conselho de Segurança, Mç. POI 751.

United Nations Archives Record Management Section

S-0904-0017-04, Country Files of the SG Kurt Waldheim, Guinea-Bissau.

S-0904-0030-01, Country Files of the SG Kurt Waldheim, Mozambique.

S-0904-0033-06, Country Files of the SG Kurt Waldheim, Portugal-Portuguese Territories.

S-0904-0039-02, Country Files of the SG Kurt Waldheim, Timor.

S-0904-0069-18, SG Kurt Waldheim, Mozambique, 28 Jun 1973-20 Dec 1976.

S-0972-0001-04, Organization of African Unity, SG Kurt Waldheim, 10 Jan-31 Dec 1975.

S-0984-0001-01, SG Meetings, Confidential Notes and Minutes, 26 Dec 1973-24 May 1974. 
S-0984-0001-02, SG Meetings, Confidential Notes and Minutes, 1974.

S-0984-0001-04, SG Meetings, Under-Secretaries-General and Assistant Secretaries-General Meetings, 9 Jan 1974-27 Aug 1975.

S-0984-0001-06, SG Meetings, Confidential Notes, SG Kurt Waldheim, 30 Dec 1975-19 Sept 1975.

S-0984-0001-07, SG Meetings, Minutes on Meetings, SG Kurt Waldheim, 10 Jan-23 Sept 1975. S-0984-0001-08, SG Meetings, Minutes on Meetings, SG Kurt Waldheim, 24 Sept-17 Dec 1975. S-0987-0004-05, SG Trips, Portugal, London, Bucharest and New York, 13 May-23 Aug 1974.

\section{Estudos}

FERREIRA, José Medeiros - "A Descolonização: seu Processo e Consequências". In MATTOSO, José - História de Portugal: Portugal em Transe (1974-1985). Vol. VIII. Lisboa: Editorial Estampa, 1994. p. 53-101.

KENT, John - America, the UN and Decolonization. Cold War Conflict in the Congo. Londres: Routledge, 2010.

MACQUEEN, Norrie - "Portugal". In THOMAS, Martin; THOMPSON, Andrew - The Oxford Handbook of the Ends of Empire. Reino Unido: Oxford University Press, 2015. p. 1-20.

OLIVEIRA, Pedro Aires - "A Descolonizaçáo Portuguesa: O Puzzle Internacional”. In ROSAS, Fernando; MACHAQUEIRO, Mário; OLIVEIRA, Pedro Aires - O Adeus ao Império: 40 Anos de Descolonização Portuguesa. Lisboa: Veja, 2015. p. 60-77.

PIMENTA, Fernando Tavares - Angola, Os Brancos e a Independência. 2a Edição. Porto: Ediçôes Afrontamento, 2016.

PIMENTA, Fernando - "Descolonização Portuguesa. Estado da Arte, Problemáticas e Fontes". Estudos do Século XX. Coimbra: IUC. No 11 (2011) p. 151-166.

PINTO, António Costa; LLOYD-JONES, Stewart - The Last Empire. Thirty Years of Portuguese Decolonization. Bristol: Intellect, 2003.

PINTO, António Costa - A Cena Internacional, a Guerra Colonial e a Descolonização. 19611975. Lisboa: Livros Horizonte, 2001.

REIS, Bruno Cardoso - Visões das Forças Políticas Portuguesas sobre o Fim do Império, Dois Planos em Confronto e uma Política Exemplar de Descolonização (1974-1975)”. In ROSAS, Fernando; MACHAQUEIRO, Mário; OLIVEIRA, Pedro Aires. O Adeus ao Império: 40 Anos de Descolonização Portuguesa. Lisboa: Veja, 2015. p. 78-101.

REZOLA, Maria Inácia - "Melo Antunes e a Descolonização: Uma História de Paixões". In REZOLA, Maria Inácia; OLIVEIRA, Pedro Aires - O Longo Curso: Estudos em Homenagem a José Medeiros Ferreira. Lisboa: Tinta-da-China, 2010. p. 517-538.

RODRIGUES, Luís Nuno - Spinola: Biografia. Lisboa: Esfera dos Livros, 2010.

RODRIGUES, Luís Nuno - "António de Spínola e o Contexto Internacional da Descolonização". In REZOLA, Maria Inácia; OLIVEIRA, Pedro Aires - O Longo Curso: Estudos em Homenagem a José Medeiros Ferreira. Lisboa: Tinta-da-China, 2010. p. 575-601.

RODRIGUES, Luís Nuno - Marechal Costa Gomes. No Centro da Tempestade. Lisboa: A Esfera dos Livros, 2008. 
RUIVO, Francisco Beirão - Spinola e a Revolução. Do 25 de Abril ao 11 de Março de 1975. Lisboa: Bertrand Editora, 2014.

SANTOS, Aurora Almada e - O Comité de Descolonização da Organização das Nações Unidas e os Movimentos de Libertação das Colónias Portuguesas: 1961-1976. Lisboa: Texto Policopiado, 2009.

SCHNEIDMAN, Witney - Confronto em África: Washington e a Queda do Império Colonial Português. Lisboa: Tribuna da História, 2005. 